\title{
Reversible ischaemia of right ventricle detected by exercise thallium-201 scintigraphy
}

\author{
AVIJIT LAHIRI, GIAN PIERO CARBONI^, JOHN W CRAWLEY, EDWARD B RAFTERY \\ From the Department of Cardiology and the Division of Radioisotopes, Northwick Park Hospital and Clinical \\ Research Centre, Harrow, Middlesex
}

SUMMARY Exercise and redistribution thallium-201 imaging is commonly used for the detection and evaluation of left ventricular ischaemia and infarction. The right ventricle is frequently visualised after stress and sometimes on redistribution images. The visualisation of the right ventricle at rest is thought to be abnormal and is suggestive of pressure or volume overload of the right ventricle, either a result of pulmonary hypertension or secondary to left ventricular dysfunction. Using stress and delayed ${ }^{201} \mathrm{Tl}$ imaging we have shown reversible left and right ventricular ischaemia and fixed left ventricular perfusion defects in two patients with multivessel coronary artery disease and left ventricular dyskinesia caused by prior myocardial infarction. Judging by the rarity of this finding as well as taking into consideration ${ }^{201} \mathrm{Tl}$ kinetics, it is suggested that reversible right ventricular ischaemia after exercise may only be detected in patients with coronary artery disease who have severely compromised ventricular function. This finding may have therapeutic and prognostic significance.

Though thallium-201 $\left({ }^{201} \mathrm{Tl}\right)$ exercise and redistribution imaging are accepted methods of detecting reversible left ventricular ischaemia resulting from coronary artery disease, ${ }^{1}$ visualisation of right ventricular ischaemia is uncommon, particularly in patients undergoing exercise ${ }^{201} \mathrm{Tl}$ imaging. The right ventricle not only has a smaller muscle mass but has less blood flow. ${ }^{2}$ Thallium-201 has a low photon energy $(69-83 \mathrm{KeV})$ so that tissue attenuation is high, and the target to background ratio is low. During exercise testing in normal subjects, however, the right ventricle can usually be visualised because the myocardial extraction fraction of ${ }^{201} \mathrm{Tl}$ is increased. This produces a high target to background ratio and both the ventricles are visualised despite the ratio between the right and left ventricles remaining unchanged. When delayed imaging is used (two to four hours), the target to background ratio falls and only the left ventricle remains visible.

The right ventricle is usually visible in exercise ${ }^{201} \mathrm{Tl}$ images in normal and compromised hearts and the right ventricle may also be observed in the left anterior oblique view in early redistribution images in normal patients. ${ }^{3}$ Visualisation of the right ventricle

^Present address: The Department of Cardiology, S. Camillo Hospital, Rome, Italy.

Accepted for publication 25 May 1982 on scans performed at rest, however, is thought to be abnormal and usually implies pressure or volume overload of the right ventricle, such as in pulmonary hypertension ${ }^{4}$ and right heart failure secondary to left ventricular failure. ${ }^{5-7}$

We have shown reversible right ventricular ischaemia associated with left ventricular dysfunction and reversible left ventricular ischaemia in two patients with coronary artery disease.

\section{Patients and methods}

EXERCISE TESTING

Maximal, symptom-related treadmill exercise testing was carried out using a modified Balke's protocol and leads CM5 and CC5 were continuously monitored (Marquette Electronics), as described elsewhere. ${ }^{8}$

\section{THALLIUM-201 SCINTIGRAPHY}

Thallium-201 imaging was carried out using the same exercise procedure as above, and $2 \mathrm{mCi}$ of ${ }^{201} \mathrm{Tl}$ was injected intravenously through a cubital vein at peak exercise. The patient then continued for a further 60 seconds at a reduced workload. Imaging was carried out in three views (anterior, 45 degrees left anterior oblique, and left lateral views) seven to 10 minutes after exercise, and redistribution imaging was carried out four hours later. ${ }^{8} \mathrm{~A}$ high resolution collimator was 
used to collect 300000 counts in each view. The counts from the abdomen were shielded with a lead sheet. The data were stored on a computer (Gamma 11, Digital) for later analysis.

The data both "raw" and digitised were reported by three trained observers with good agreement. The computer was used to remove $40 \%$ of the lower threshold and nine point smoothing was carried out.

A positive identification of a perfusion defect was made semiquantitatively when there was $50 \%$ or more reduction of counts in the ventricular wall as compared with a region of maximal myocardial count density containing about 5000 counts in a selected region of interest. Quantitative analysis of the relative lung uptake of ${ }^{201} \mathrm{Tl}$ was also carried out. ${ }^{10}$

\section{MULTIPLE GATED BLOOD POOL ANGIOGRAPHY}

Gated blood pool angiography was carried out using $20 \mathrm{mCi}$ of technetium- $99 \mathrm{~m}\left({ }^{99 \mathrm{~m}} \mathrm{Tc}\right)$ labelled red blood cells. Three million counts were recorded in the anterior and left anterior oblique views (40 degrees LAO with a 10 degree caudal tilt). Data were stored on a hard disc (Gamma 11, digital) and analysed using the method of Maddox et al. ${ }^{11}$ to obtain global ejection fractions and to assess regional left ventricular wall motion.

\section{CONTRAST ANGIOGRAPHY}

Contrast left ventricular angiography and coronary arteriography were carried out using the Judkins technique and multiple views were obtained.

\section{Case reports}

CASE 1

A 46 year old man presented with exertional angina nine months after an anterior myocardial infarction. Exercise testing showed $3 \mathrm{~mm}$ ST segment elevation over leads presenting with " $Q$ " waves in CM5 and CC5. The patient stopped at four minutes because of chest pain. Thallium-201 scintigraphy showed an enlarged heart, increased lung uptake of ${ }^{201} \mathrm{Tl}$, an anterior wall perfusion defect (fixed), and reversible perfusion defects of the inferior wall and of the inferior part of the right ventricle (Fig. 1). Multiple gated blood pool angiography showed apical dyskinesia, anterior akinesia, and septal hypokinesia of the left ventricle. The calculated ejection fraction was $19 \%$. Coronary arteriography disclosed complete proximal left anterior descending coronary artery occlusion $(100 \%), 90 \%$ narrowing of the proximal right coronary artery with diffuse disease, and a nondominant left circumflex coronary artery with less than $50 \%$ narrowing. There was no established collateral circulation. Left ventricular angiography confirmed the findings of the radionuclide angiogram and a dyskinetic anteroapical aneurysm was demonstrated.

\section{CASE 2}

A 41 year old man with a history of a previous anterior myocardial infarction 14 months ago presented with mild exertional angina. Exercise testing showed ST segment depression in CM5 and CC5 (2 mm in CC5) after nine minutes and the test was discontinued because he developed dyspnoea and slight chest pain. Thallium-201 imaging showed a fixed anterior wall perfusion defect. Reversible ischaemia was noted in the posterolateral left ventricular wall and in the free right ventricular wall (Fig. 2). Increased lung uptake of ${ }^{201} \mathrm{Tl}$ was also shown. Radionuclide angiography disclosed akinesia of the anterior and apical left ventricular wall. The calculated resting ejection fraction was $26 \%$. Subsequent coronary arteriography showed complete occlusion of the left anterior descending coronary artery (100\%) distal to a large marginal

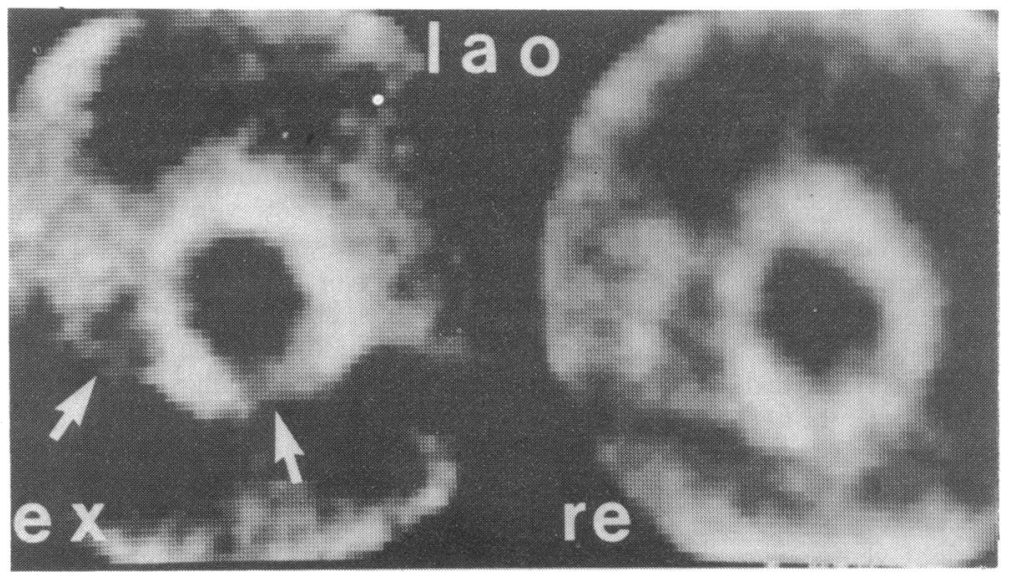

Fig. $1 L A O-45^{\circ}{ }^{201} \mathrm{Tl}$ images after exercise testing (ex) and redistribution (re) four hours after exercise. The exercise image shows photon deficient areas in the inferior wall of the left ventricle and the inferior part of the free right ventricle (arrows). The redistribution image shows normalisation of the exercise perfusion defects and a persistent right ventricular image, which is an abnormal finding on delayed images and is suggestive of right ventricular overloading. 


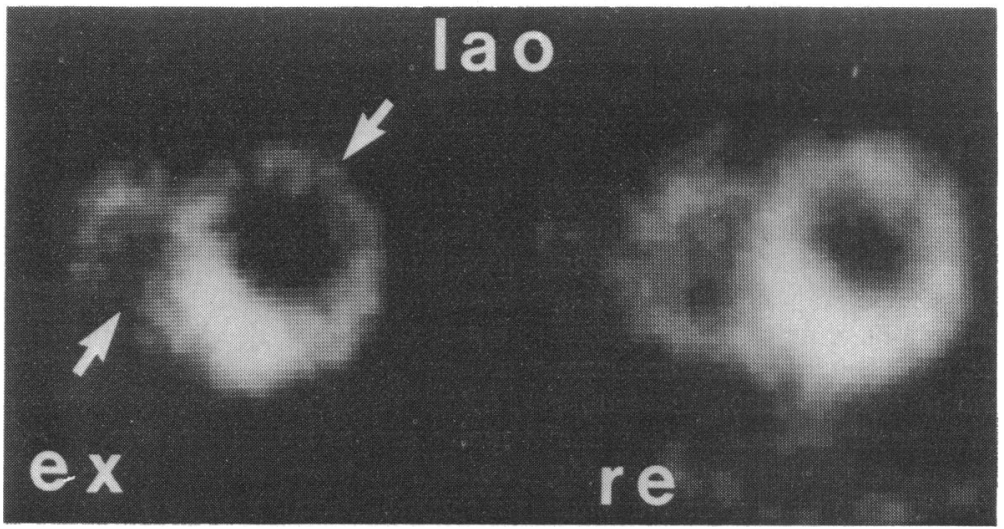

Fig. $2 L A O-45^{\circ} 201 T l$ images after exercise testing (ex) and redistribution (re) four hours after exercise. The exercise scan shows perfusion defects in the lateral wall and in the inferior segment of the right ventricle (arrows). These defects return to normal on delayed images (re), but the persistent right ventricular image is suggestive of right ventricular overloading.

branch which had a $70 \%$ stenosis at its origin. The occluded left anterior descending artery filled retrogradely from its stenosed marginal branch. The left circumflex coronary artery had an irregular lumen with a $70 \%$ stenosis at the middle and the right coronary artery was normal. Contrast left ventricular angiography confirmed the presence of an anteroapical aneurysm.

\section{Discussion}

Necropsy studies have shown that the posterior left ventricular wall is always involved in right ventricular infarction and that there is a 50 to $75 \%$ chance of right ventricular involvement with inferior and inferoseptal left ventricular infarctions. ${ }^{12}$ Candell-Riera et al. ${ }^{13}$ using lead RV4 during exercise, echocardiography, haemodynamic studies, and ${ }^{99 \mathrm{~m}} \mathrm{Tc}$ myocardial infarction imaging detected right ventricular involvement in more than $50 \%$ of patients with acute inferior wall infarction. Thus, one may extrapolate from these data and postulate that exercise-induced right ventricular ischaemia may occur in association with reversible ischaemia of the inferior wall (right coronary artery territory) and/or lateral and posterolateral walls (left coronary artery territory) of the left ventricle. The demonstration, however, of reversible right ventricular ischaemia using exercise and delayed redistribution imaging with ${ }^{201} \mathrm{Tl}$ will only be possible when the right ventricle becomes visible either because of an increase in right ventricular overload secondary to left ventricular dysfunction or because of the presence of pulmonary hypertension.

In a recent report, Brachman et al. ${ }^{14}$ described reversible ischaemia of the right ventricle in two patients with multiple vessel disease. Early redistribution scans (40 minutes) rather than delayed postexercise imaging (four hours) were reported to be of value for demonstrating reversible right ventricular ischaemia, and it was thought that this finding would improve the sensitivity of detecting right coronary artery disease. ${ }^{14} \mathrm{We}$ have shown reversible right ventricular ischaemia in two patients, however, using only the post-exercise and the delayed (four hours) scans. Furthermore, right ventricular ischaemia was demonstrated in the presence of a normal right coronary artery (case 2). Our patients not only showed evidence of depressed left ventricular function at rest but developed indications of exercise-induced left ventricular dysfunction and heart failure as evidenced by exercise-induced ST segment elevation in one (case $1)^{7}$ and increased lung uptake of ${ }^{201} \mathrm{Tl}$ in both patients. 9101516

The vascular supply of the right ventricle is usually from the right coronary (90\%) and from the left circumflex coronary (10\%) arteries. ${ }^{13}$ Slutsky et al. ${ }^{17}$ using exercise radionuclide angiography, showed a reduction of right ventricular ejection fraction in patients with either right or left coronary artery disease. They suggested that this might be secondary to left ventricular dysfunction associated with ischaemia of the left and right ventricles.

Wackers et al., ${ }^{18}$ using a dual isotope technique, found that $37.5 \%$ of patients with acute inferior wall infarction concentrated ${ }^{99 m} \mathrm{Tc}$-stanilous pyrophosphate $\left({ }^{99 m} \mathrm{Tc}\right.$-pyp) in the right ventricle, whereas ${ }^{201} \mathrm{Tl}$ imaging identified left ventricular perfusion defects in all. This report, ${ }^{18}$ however, did not mention the number of patients who had increased right ventricular concentration of ${ }^{201} \mathrm{Tl}$. Sharpe et al. ${ }^{19}$ reported similar findings using gated radionuclide angiography, ${ }^{99 m} \mathrm{Tc}$-pyp, and $\mathrm{M}$-mode echocardiography, and found that right ventricular function was impaired in patients with acute inferior infarction in whom ${ }^{99 \mathrm{~m}} \mathrm{Tc}$-pyp concentrated in the right ventricle. 0 The limitation of ${ }^{99 m} \mathrm{Tc}$-pyp is that it can only be used with moderate success in acute infarction and not in $\stackrel{\mathbb{D}}{\circ}$ patients such as we have investigated. Sugrue et al. ${ }^{20} \frac{}{\mathbb{D}}$ 
described an attractive method for calculating selective right ventricular ejection fraction using ultra short lived ${ }^{81 \mathrm{~m}} \mathrm{Kr}\left(\mathrm{T}^{1} / 2=13 \mathrm{~s}\right)$ given as an intravenous infusion. Using this method it is feasible that stress studies may be carried out in order to detect right ventricular ischaemia. Quantitative myocardial blood flow measurements to the right ventricle may be obtained by using single photon emission tomography and intraventricular injection of microspheres. ${ }^{21}$

In our institution we have not previously noted right ventricular ischaemia while assessing early redistribution in patients with coronary artery disease. ${ }^{8}$ We feel that the early visualisation of the right ventricle, in the two cases reported by Brachman et al. ${ }^{14}$ was probably the result of increased right ventricular overload secondary to exercise-induced left ventricular dysfunction in patients with multiple vessel disease.

Demonstration of reversible right ventricular ischaemia may be the result of either right or left coronary artery disease. The presence of associated reversible regional left ventricular ischaemia may be helpful in identifying the diseased coronary artery responsible for the dominant vascular supply to the right ventricle. In the presence, however, of established collateral circulation ${ }^{201} \mathrm{Tl}$ perfusion defects may not be visualised in patients with significant coronary occlusion. ${ }^{22}$

Though the concept of detecting right ventricular ischaemia with ${ }^{201} \mathrm{Tl}$ is an attractive one, the physical characteristic of ${ }^{201} \mathrm{Tl}$ and the difference between right and left ventricular blood flow make this a difficult application.

The presence of reversible right ventricular ischaemia on exercise and redistribution ${ }^{201} \mathrm{Tl}$ images implies that either the right or left coronary artery is stenosed and that there is either pressure or volume loading of the right ventricle. In the presence of both left and right ventricular ischaemia one may be able to identify the coronary artery lesion responsible for right ventricular ischaemia. This finding may have therapeutic and prognostic significance, since occlusion of the jeopardised coronary artery is likely to produce a biventricular failure which is more resistant to treatment. When considering medical treatment, afterload and preload reducing agents may help to improve ventricular function.

\section{References}

1 Pohost GM, Zir LM, Moore RH, McKusick KA, Guiney TE, Beller GA. Differentiation of transiently ischemic from infarcted myocardium by serial imaging after single dose of thallium-201. Circulation 1977; 55: 294-302.

2 Ter-Pogossian MM, Klein MS, Markham J, Roberts R,
Sobel BE. Regional assessment of myocardial metabolic integrity in vivo by positron-emission tomography with ${ }^{11}$ C-labeled palmitate. Circulation 1980; 61: 242-55.

3 Berman DS, Garcia EV, Maddahi J. Role of Thallium201 imaging in the diagnosis of myocardial ischaemia and infarction. In: Freeman LM, Weissman HS, eds. Nuclear medicine annual, 1980. New York: Raven Press, 1980: 1-55.

4 Cohen HA, Baird MG, Rouleau JR, et al. Thallium-201 myocardial imaging in patients with pulmonary hypertension. Circulation 1976; 54: 790-5.

5 Khaja F, Alam M, Goldstein S, Anbe DT, Marks DS. Diagnostic value of visualization of the right ventricle using thallium-201 myocardial imaging. Circulation 1979; 59: $182-8$.

6 Rosenblatt A, Lowenstein JM, Kerth W, Handmaker H. Post-exercise thallium-201 myocardial scanning: a clinical appraisal. Am Heart $f$ 1977; 94: 463-70.

7 Lahiri A, Balasubramanian V, Millar-Craig MW, Crawley J, Raftery EB. Exercise-induced ST segment elevation: electrocardiographic, angiographic and scintigraphic evaluation. $\mathrm{Br}$ Heart $\mathcal{F}$ 1980; 43: 582-8.

8 Lahiri A, Balasubramanian V, Millar-Craig MW, Crawley J, Raftery EB. Exercise-induced ST-segment elevation in variant angina. Am $\mathcal{F}$ Cardiol 1980; 45: 887-94.

9 Lahiri A, Sonecha TN, Crawley JW, Balasubramanian $\mathrm{V}$, Raftery EB. Is exercise-induced pulmonary ${ }^{201} \mathrm{Tl}$ uptake in post-infarction patients a sensitive prognostic indicator? (abstract) Clin Sci 1981; 62: 37.

10 Lahiri A, Spencer J, Crawley JW, Raftery EB. Pulmonary uptake of thallium-201 in acute pulmonary oedema. Br $\mathcal{F}$ Radiol 1982; 55: 460-3.

11 Maddox DE, Wynne J, Uren R, et al. Regional ejection fraction: a quantitative radionuclide index of regional left ventricular performance. Circulation 1979; 59: 1001-9.

12 Isner JM, Roberts WC. Right ventricular infarction complicating left ventricular infarction secondary to coronary heart disease. Am $\mathcal{F}$ Cardiol 1978; 42: 885-94.

13 Candell-Riera J, Figueras J, Valle V, et al. Right ventricular infarction: relationships between ST-segment elevation in V4R and hemodynamic, scintigraphic, and echocardiographic findings in patients with acute inferior myocardial infarction. Am Heart $\mathcal{F}$ 1981; 101: 281-7.

14 Brachman MB, Rozanski A, Charuzi Y, Maddahi J, Waxman AD, Berman DS. Thallium-201 stress redistribution abnormalities of the right ventricle: a manifestation of proximal right coronary artery stenosis. Am Heart $\mathcal{F}$ 1981; 101: 288-91.

15 Bingham JB, McKusick KA, Strauss HW, Pohost GM. Influence of coronary artery disease on pulmonary uptake of thallium-201. Am $f$ Cardiol 1980; 46: 821-31.

16 Kushner FG, Okada RD, Kirshenbaum HD, Boucher CA, Strauss HW, Pohost GM. Lung thallium-201 uptake after stress testing in patients with coronary artery disease. Circulation 1981; 63: 341-7.

17 Slutsky R, Hooper W, Gerber K, et al. Assessment of right ventricular function at rest and during exercise in patients with coronary heart disease: a new approach using equilibrium radionuclide angiography. $\mathrm{Am} \mathcal{F} \mathrm{Car}-$ diol 1980; 45: 63-71.

18 Wackers FJT, Lie KI, Sokole EB, et al. Prevalence of right ventricular involvement in inferior wall infarction 
assessed with myocardial imaging with thallium-201 and technitium-99m pyrophosphate. Am $\mathcal{F}$ Cardiol 1978; 42: 358-62.

19 Sharpe DN, Botvinick EH, Shames DM, et al. The noninvasive diagnosis of right ventricular infarction. Circulation 1978; 57: 483-90.

20 Sugrue DD, Kamal S, Rozkovec A, McKenna WJ, Oakley CM, Lavender JP. A new method for the measurement of right ventricular function using ultra short-lived isotope (Krypton-81m) (abstract). F Nucl Med 1981; 22: p8.

21 Lavender JP, Maseri A, Davies GJ, Oliveira B, Sugrue $D$, Myers $M$. The distribution of cardiac output in man recorded by intraventricular injection of microspheres (abstract). $\mathcal{F}$ Nucl Med 1981; 22: p30.

22 Rigo P, Becker LC, Griffith LSC, et al. Influence of $\stackrel{\vec{F}}{+}$ coronary collateral vessels on the results of thallium-201 myocardial stress imaging. Am $\mathcal{F}$ Cardiol 1979; 44: 4528.

Requests for reprints to Dr Edward B Raftery, Department of Cardiology, Northwick Park Hospital and Clinical Research Centre, Watford Road, Harrow, Middlesex HAl 3UJ. 